\title{
Xanthates: Metabolism by Flavoprotein-Containing Monooxygenases and Antimycobacterial Activity
}

\author{
Stanislav G. Yanev, Tsveta D. Stoyanova, Violeta V. Valcheva, and Paul R. Ortiz de Montellano \\ Department of Drug Toxicology, Institute of Neurobiology (S.G.Y., T.D.S.), and Institute of Microbiology (V.V.V.), Bulgarian Academy \\ of Sciences, Sofia, Bulgaria; and Department of Pharmaceutical Chemistry, University of California, San Francisco, \\ California (P.R.O.M.)
}

Received April 10, 2018; accepted May 16, 2018

\begin{abstract}
Ethionamide (ETH) plays a central role in the treatment of tuberculosis in patients resistant to the first-line drugs. The ETH, thioamide, and thiourea class of antituberculosis agents are prodrugs that are oxidatively converted to their active $S$-oxides by the mycobacterial flavin-dependent monooxygenase (EtaA) of Mycobacterium tuberculosis, thus initiating the chain of reactions that result in inhibition of mycolic acid biosynthesis and cell lysis. As part of a search for new lead candidates, we report here that several xanthates are oxidized by purified EtaA to $S$-oxide metabolites (perxanthates), which are implicated in the antimycobacterial activity of these compounds.
\end{abstract}

This process, which is analogous to that responsible for activation of ETH, is also catalyzed by human flavoprotein monooxygenase 3 . EtaA was not inhibited in a time-dependent manner during the reaction. Xanthates with longer alkyl chains were oxidized more efficiently. EtaA oxidized octyl-xanthate $\left(K_{\mathrm{m}}=5 \mu \mathrm{M} ; V_{\max }=\right.$ $1.023 \mathrm{nmolP} / \mathrm{min} ; \boldsymbol{k}_{\text {cat }}=\mathbf{5 . 2} \mathrm{molP} / \mathrm{min} / \mathrm{molE}$ ) more efficiently than ETH (194 $\mu \mathrm{M}$; $1.46 \mathrm{nmolP} / \mathrm{min} ; 7.73 \mathrm{nmolP} / \mathrm{min} / \mathrm{molE}$, respectively). Furthermore, the in vitro antimycobacterial activity of four xanthates against $M$. tuberculosis $\mathrm{H} 37 \mathrm{Hv}$ was higher (minimum inhibitory concentration of around $1 \mu \mathrm{M})$ than that of ETH (12 $\mu \mathrm{M})$.

\section{Introduction}

The increasing resistance of pathogenic bacteria and viruses against the available antibiotic and chemotherapeutic agents is one of the major problems of modern healthcare. At the top of the list of diseases affected by this resistance are AIDS, influenza, and tuberculosis. The genetic variability of Mycobacterium tuberculosis (Mtb) underlies the current treatment consisting of a cocktail of several first-line drugs. In the case of resistance to this treatment, therapy resorts to second-line drugs. The available antituberculosis drugs as well as those under development, attack Mtb at several target points, including the bacterial cell wall. Isoniazid, ethionamide (ETH), and prothionamide inhibit the enoyl-acyl carrier protein reductase InhA, a key enzyme in cell wall assembly. All three of these agents are prodrugs that must be activated to become effective (Banerjee et al., 1994; Johnsson et al., 1995). These three drugs specifically disrupt mycolic acid synthesis by forming adducts with NADH that inhibit InhA, thus blocking the synthesis of mycolic acids, key factors in cell envelope permeability, host immunomodulation, and persistence of Mtb (Daffé et al., 2017).

Isoniazid is activated by the catalase-peroxidase hemoprotein KatG (Zhang et al., 1992). However, ETH, a second-line drug, is a sulfurcontaining compound that must be activated to its $S$-oxide by the mycobacterial flavin-dependent monooxygenase (EtaA) to exert its bacteriostatic action (Baulard et al., 2000). Flavoprotein monooxygenases (FMOs) belong to a large group of flavin oxygenases found in species ranging from microorganisms to mammals. These enzymes are

This research was supported by the National Institutes of Health [Grant Al074824].

https://doi.org/10.1124/dmd.118.081984. characterized by the NADPH-dependent reduction of an enzyme-bound flavin, leading to formation of the active oxidizing species, a C4a-flavin (hydro) peroxide (Phillips and Shephard, 2017).

Human FMO enzymes perform $N$ - or $S$-oxygenation of nucleophilic heteroatom-containing small exogenous and endogenous molecules and are grouped into five classes depending on their sequence, structure, organ distribution, genetic control, and substrate specificity. FMO1 is expressed in human fetal liver and adult human kidney and intestine; FMO4 is expressed in kidney and brain; and the highly polymorphic enzyme FMO2 is expressed in the lung. Today, $26 \%$ of individuals of African descent and $5 \%$ of Hispanics carry at least one allele coding for FMO2.1, which has very high activity for $S$-oxidation of thioureas and thus increases the risk for lung toxicity in tuberculosis patients treated with ETH (Krueger et al., 2002). The primary flavin-dependent monooxygenase in human liver is FMO3, which participates in the oxidation of a number of nitrogen- and sulfur-containing compounds (Cashman and Zhang, 2006).

Classic, so-called Baeyer-Villiger monooxygenases generate reactive (hydro) peroxide intermediates that carry out both nucleophilic and electrophilic oxygenations. In contrast to classic Baeyer-Villiger reactions, when the Baeyer-Villiger monooxygenase EtaA oxidizes sulfur-containing substrates, its $\mathrm{C} 4 \mathrm{a}$-adduct is most likely reacting as a hydroperoxide rather than as a peroxide (Ballou and Entsch, 2013). The heterologous expression and purification of EtaA has made the enzyme available for testing the metabolism of heteroatom-containing compounds under in vitro conditions (Vannelli et al., 2002). Studies of the reactivity of xanthates with oxygen in the presence of metals have shown that the primary oxidation products with hydrogen peroxide are the corresponding sulphines or perxanthates (Silvester et al., 2002).

Xanthates are salts of different derivatives of dithiocarbonic acid that have a large spectrum of biologic effects. These include antiviral,

ABBREVIATIONS: DMSO, dimethylsulfoxide; D609, O-tricyclo[5.2.1.02,6]dec-9-yl-dithiocarbonate; EtaA, mycobacterial flavin-dependent monooxygenase; ETH, ethionamide; FMO, flavoprotein monooxygenase; Mtb, Mycobacterium tuberculosis. 
anticancer, and chelating effects, as well as the inhibition of several enzymes of importance in intercellular signaling processes (Adibhatla et al., 2012). In 1956, Ivanov and coworkers published data indicating that different xanthate derivatives have an antibacterial action against Mtb due to their oxidation to toxic metabolites (Ivanov, 1956).

Here, we present the results from the study of metabolism of several xanthates by EtaA and FMO3 to $S$-oxygenated metabolites, and compare the antimycobacterial properties of the resulting metabolites with those from ETH. The results suggest that this metabolic activation is essential for their antimycobacterial action.

\section{Experimental Procedures}

\section{Materials}

Potassium salts of various derivatives of dithiocarbonic acid (xanthates, $\mathrm{ROCS}_{2} \mathrm{~K}$, where $\mathrm{R}$ corresponds to alkyl groups with $\mathrm{C} 1$, C2, C3, C3iso, 2-methyl-C3, C4, C5, C8, C10, and C12 carbon atoms, or a cyclohexene ring; for example, $\mathrm{C} 3=$ propylxanthate $=$ $\mathrm{CH}_{3} \mathrm{CH}_{2} \mathrm{CH}_{2} \mathrm{COS}_{2}^{-} \mathrm{K}^{+}$), were synthesized as previously described (Rao, 1971). ETH, $O$-tricyclo[5.2.1.02,6]dec-9-yl-dithiocarbonate (D609), NADPH, bovine serum albumin, superoxide dismutase, catalase, and all other chemical reagents were purchased from Sigma-Aldrich Chemical Co. (St. Louis, MO). Human liver FMO3 was obtained from BD Biosciences (San Jose, CA). Purified EtaA was kindly provided by Dr. Clinton Nishida (University of California, San Francisco, San Francisco, CA).

\section{Spectrophotometric Analyses}

The metabolism of various xanthates was studied spectrophotometrically. Stock solutions of various xanthates were prepared in water, C10 and $\mathrm{C} 12$ were dissolved in dimethylsulfoxide (DMSO), and ETH was dissolved in acetonitrile. The final organic solvent concentration was held to $0.1 \%(\mathrm{v} / \mathrm{v})$.

Xanthates, ETH, and Hydrogen Peroxide. Spectral changes of xanthates and ETH in $0.1 \mathrm{M}$ phosphate buffer, $\mathrm{pH}=7.4$, were determined after incubation with $10 \mathrm{mM}$ hydrogen peroxide.

Xanthate, ETH, and EtaA. The final reaction medium contained EtaA (400 $\mathrm{nM})$, bovine serum albumin $(0.1 \mathrm{mg} / \mathrm{ml})$, superoxide dismutase $(100 \mathrm{U} / \mathrm{ml})$, catalase $(100 \mathrm{U} / \mathrm{ml}), \mathrm{KCl}(100 \mathrm{mM}), \mathrm{NADPH}$ $(200 \mu \mathrm{M})$, and different concentrations of xanthates in HEPES buffer $(50 \mathrm{mM}, \mathrm{pH}=7.5)$. When used, the NADPH regenerating system consisted of glucose-6-phosphate $(2.5 \mathrm{mM})$ and glucose-6-phosphate dehydrogenase $(2 \mathrm{U} / \mathrm{ml})$. After 2 -minute preincubation at $37^{\circ} \mathrm{C}$ the reaction was initiated by adding the enzyme to the sample cuvette and an equal volume of water to the reference cuvette in a Varian Cary 300 Bio dual-beam spectrophotometer (Varian, Inc., Palo Alto, CA).

Spectral scans between 250 and $400 \mathrm{~nm}$ were recorded every 30 seconds at a scan rate of $1515 \mathrm{~nm} / \mathrm{min}$ and a spectral bandwidth of $4 \mathrm{~nm}$. A baseline of the reaction mixture in the two cuvettes was collected prior to addition of the enzyme. The rates of substrate consumption and product formation were determined at $301 \mathrm{~nm}\left(\varepsilon=17,600 \mathrm{M}^{-1} / \mathrm{cm}^{-1}\right)$ and $347 \mathrm{~nm}\left(\varepsilon=10,400 \mathrm{M}^{-1} / \mathrm{cm}^{-1}\right)$, respectively (Hao et al., 2000). Single-wavelength kinetic studies were conducted at either 321 or $347 \mathrm{~nm}$ for the observation of either NADPH $\left(\varepsilon=4752 \mathrm{M}^{-1} \mathrm{~cm}^{-1}\right)$ consumption or product formation, respectively.

Xanthates and FMO3. The same experimental protocol as previously described was used to follow the spectral changes between 250 and $400 \mathrm{~nm}$ after incubation of xanthates with FMO3. For kinetic studies, both the reference and sample cuvettes were charged with a $500 \mu \mathrm{l}$ volume of buffer containing the desired xanthate at a $200 \mu \mathrm{M}$ final concentration. The reaction was started by adding NADPH $(200 \mu \mathrm{M})$ and enzyme protein $(50 \mu \mathrm{g}, 60$ pmol flavin adenine dinucleotide) to the sample cuvette and its progress was followed by recording the absorption changes at $347 \mathrm{~nm}$ for 5 minutes at $37^{\circ} \mathrm{C}$.

\section{Antimycobacterial Activity of Xanthates and ETH}

The in vitro antimycobacterial activity of C2, C5, C8, D609, and ETH was determined through the proportional method of Canetti et al. (1969) toward reference strain Mtb H37Rv. Each compound was tested at seven concentrations: $10,5,2,1,0.5,0.2$, and $0.1 \mu \mathrm{g} / \mathrm{ml}$ in DMSO. Tubes with Löwenstein-Jensen medium $(5 \mathrm{ml})$ containing tested compounds and those without them (controls) were inoculated with $0.1 \mathrm{ml}$ suspension of Mtb H37Rv $\left(10^{5}\right.$ cells $\left./ \mathrm{ml}\right)$ and incubated for 45 days at $37^{\circ} \mathrm{C}$. The ratio between the number of colonies of Mtb grown in medium containing compounds and the number of colonies in control medium was calculated and expressed as percentage of inhibition. The minimum inhibitory concentration is defined as the minimum concentration of compound (in micromolars) that is required to inhibit bacterial growth completely ( $0 \%$ growth).

\section{Statistics}

Nonlinear and linear regression analyses to calculate the enzyme kinetic parameters were done using GraphPad Prism 6.0 (GraphPad Software, La Jolla, CA). Paired $t$ test was applied for statistical comparison of the enzyme activity data.
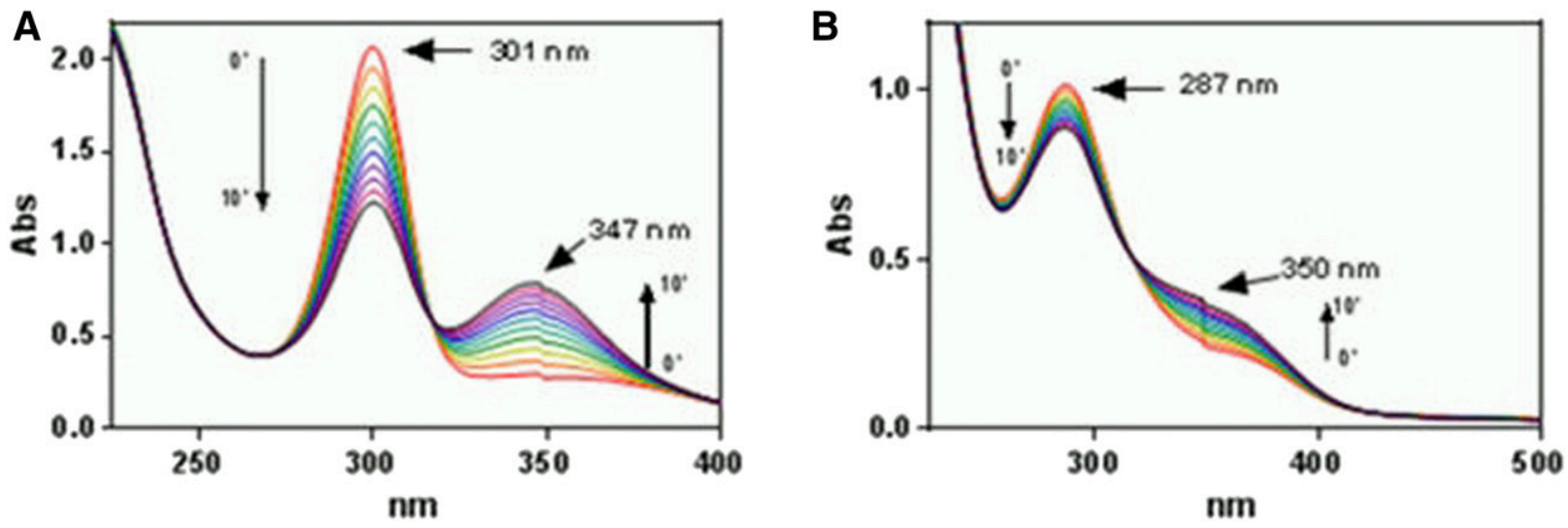

Fig. 1. Spectral changes of (A) C5-xanthate $(50 \mu \mathrm{M})$ and (B) ETH $(200 \mu \mathrm{M})$ in $0.1 \mathrm{M}$ phosphate buffer, pH 7.4, by 10 mM hydrogen peroxide. 

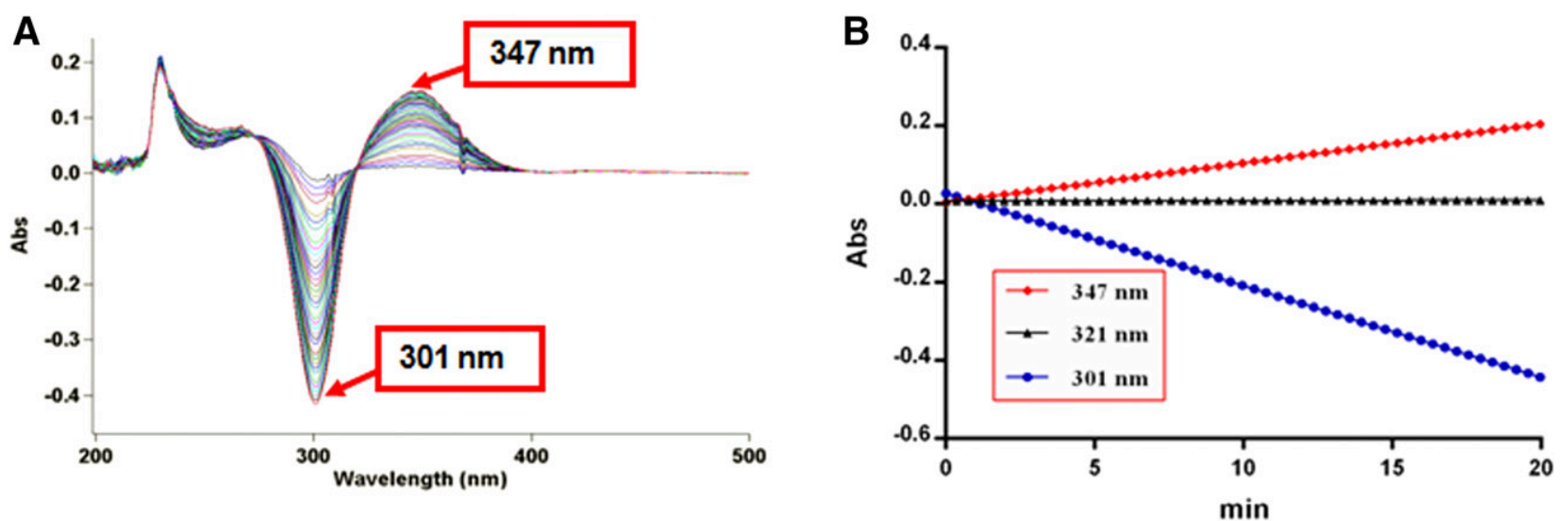

Fig. 2. (A) Spectroscopic characteristics of metabolism of octyl xanthate $(80 \mu \mathrm{M})$ by EtaA measured over 20 minutes. (B) Changes in absorption over time at $301 \mathrm{~nm}$ (blue), $321 \mathrm{~nm}$ (black), and $347 \mathrm{~nm}$ (red).

\section{Results}

\section{Oxidation of Xanthates and ETH by Hydrogen Peroxide}

Hydrogen peroxide oxidizes xanthates and ETH to single metabolites: perxanthate or sulfine $\left(\lambda_{\max }\right.$ at $\left.347 \mathrm{~nm}\right)$ and ETH-S-oxide $\left(\lambda_{\max }\right.$ around $350 \mathrm{~nm}$ ), respectively (Fig. 1). The sharper increase of perxanthate over time compared with that of ETH-S-oxide was not only due to the higher extinction coefficient of the former $\varepsilon=10,400 \mathrm{M}^{-1} / \mathrm{cm}^{-1}$ (Hao et al., 2000) versus $\varepsilon=6000 \mathrm{M}^{-1} / \mathrm{cm}^{-1}$ (Vannelli et al., 2002), but due to the fact that the rate of oxidation of $\mathrm{C} 5$-xanthate by $\mathrm{H}_{2} \mathrm{O}_{2}$ to its metabolite was more than two times faster $(2.34 \mathrm{nmol} / \mathrm{min})$ compared with that of ETH $(1.0 \mathrm{nmol} / \mathrm{min})$. It is important to note that the oxidation of ETH to ETH-SO by $\mathrm{H}_{2} \mathrm{O}_{2}$ occurs without the assistance of any cofactor such as $\mathrm{NAD}^{+}$(Laborde et al., 2016).

\section{Metabolism of Xanthates by EtaA}

Scanning Kinetics. Initial metabolism studies with an NADPH regenerating system and EtaA enabled the direct observation and comparison of product formation and substrate consumption rates. These data for a sampling of xanthate substrates are presented in Fig. 2A and Table 1.

The substrate consumption (decrease in absorption at $301 \mathrm{~nm}$ ) and product formation (increase in absorption at $347 \mathrm{~nm}$ ) rates after incubation with EtaA correlate well, indicating conversion of the substrate to a single product, the corresponding perxanthate. The presence of a clear isosbestic point at $321 \mathrm{~nm}$ (Fig. 2A) supports the conclusion that the substrate is converted to a single product. It is to be noted that with the longer straight chain alkyl-xanthates (i.e.,

TABLE 1

Metabolism of different xanthates $(100 \mu \mathrm{M})$ by EtaA $(400 \mathrm{nM})$

The rates of the decrease in the substrate at $301 \mathrm{~nm}$ and increase in the product at $347 \mathrm{~nm}$ are presented. Values are the mean \pm S.D. from three different experiments.

\begin{tabular}{lcc}
\hline \multicolumn{1}{c}{ Xanthate } & $V_{301}$ & $V_{347}$ \\
\hline & nmol/min & nmol/min \\
C3 & $-1.27 \pm 0.07$ & $0.97 \pm 0.077$ \\
2-methyl-C3 & $-0.38 \pm 0.06$ & $0.22 \pm 0.012$ \\
C4 & $-1.57 \pm 0.12$ & $0.93 \pm 0.065$ \\
C5 & $-1.53 \pm 0.09$ & $0.74 \pm 0.052$ \\
C8 & $-1.35 \pm 0.08$ & $0.90 \pm 0.072$ \\
Cyclo & $-0.8 \pm 0.07$ & $0.71 \pm 0.064$ \\
C10 & $-2.47 \pm 0.18$ & $0.49 \pm 0.110$ \\
C12 & $-1.51 \pm 0.10$ & $0.03 \pm 0.007$ \\
D609 & $-0.89 \pm 0.08$ & $0.58 \pm 0.040$ \\
\hline
\end{tabular}

decyl- and dodecyl-xanthates) there was a discrepancy between the higher rates of substrate depletion and the lower rates of product formation. This discrepancy could be due to aggregation and subsequent precipitation of the product of the longer substrates in the aqueous solution. Xanthates bearing cyclic or branched side chains (2-methylC3, Cyclo, and D609) were metabolized by EtaA at a significantly slower rate.

Steady-State Kinetics. The dependence of the C8 oxidation rate on the substrate concentration follows the Michaelis-Menten equation. Figure 3 presents the best fit through the data set obtained and the approximate kinetic values are based on that fit. The maximum rate of oxidation of C8-xanthate by EtaA was practically the same as that previously obtained for ETH $\left(V_{\max }=1.46 \mathrm{nmolP} / \mathrm{min}\right.$ and 7.73 $\mathrm{molP} / \mathrm{min} / \mathrm{molE}$, respectively). It is important to note that the $k_{\text {cat }}$ values for the oxidation of most substrates by EtaA are nearly the same. This is due to the fact that the rate-limiting step in the FMO catalytic cycle is the release of water from the enzyme with the concomitant dehydration of the C4a-flavin hydroxide (Beaty and Ballou, 1981).

However, the $K_{\mathrm{m}}$ value shows that $\mathrm{C} 8$ has a much higher affinity for EtaA than ETH ( $K_{\mathrm{m}}=5 \mu \mathrm{M}$ vs. $194 \mu \mathrm{M}$, respectively) (Vannelli et al., 2002). Stopped flow studies show that the $K_{\mathrm{m}}$ values for $S$-oxygenatable substrates depend largely on their reactivity with the hydroxyperoxyflavin rather than on their interaction with enzyme protein. The

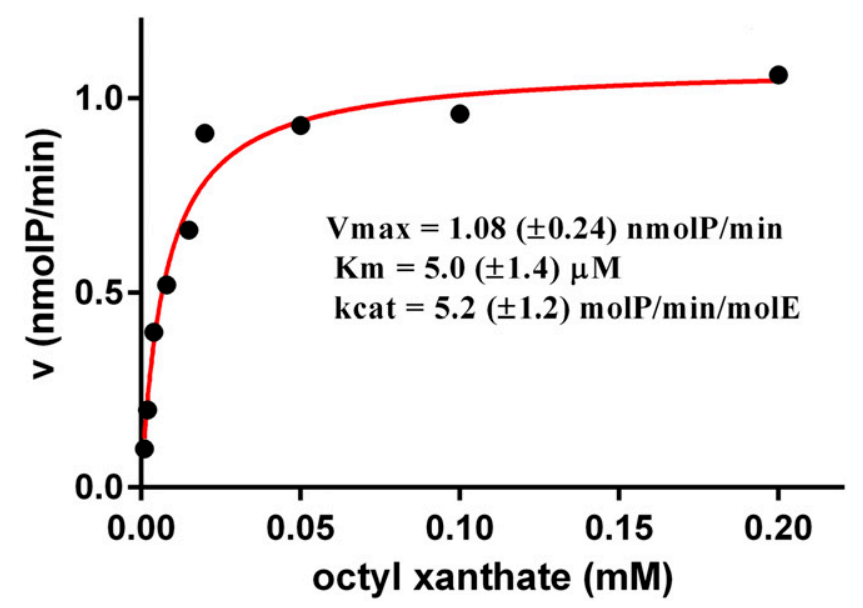

Fig. 3. Steady-state kinetics of the oxidation of octyl xanthate by EtaA. The red line represents the best nonlinear curve fit $\left(r^{2}=0.9749\right)$. The Michaelis-Menten parameters are represented as mean \pm S.D. from three different experiments. 
A

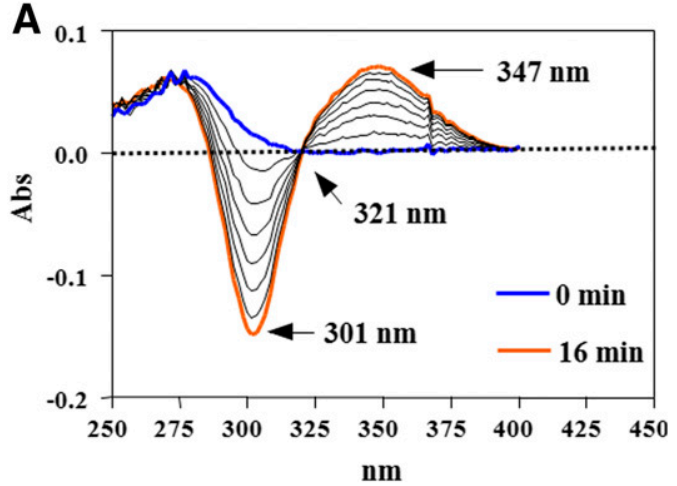

B

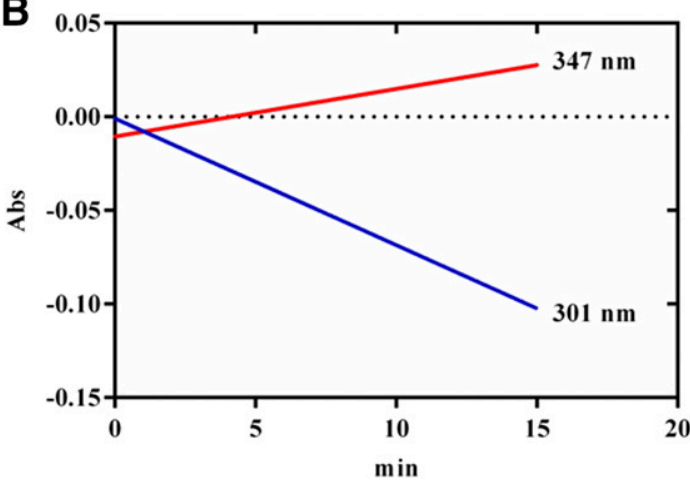

Fig. 4. (A) Spectroscopic characteristics of cyclohexyl xanthate $(80 \mu \mathrm{M})$ after incubation with human FMO3; (B) Rate of metabolism of 2-methylpropyl xanthate (80 $\mu \mathrm{M})$ on incubation with human FMO3.

determining factor is the nucleophilicity of the sulfur atom (Poulsen and Ziegler, 1995), which in all tested xanthates is significantly higher than that of ETH. The higher reactivity of the xanthates was consistent also with the higher rate of oxidation by hydrogen peroxide.

\section{Metabolism of Xanthates by Human Isozyme FMO3}

Similar results were also obtained by examining the metabolism of xanthates to $S$-oxidative products (perxanthates) by human liver FMO3 (Fig. 4). The results from tracking the rate of formation of the perxanthate metabolites from different xanthates by FMO3 are listed in Table 2. The results show that the rate of $S$-oxidation increases with increasing number of carbon atoms in the alkyl chain substituent in incubations of xanthates with EtaA and FMO3. Thus, C8 was oxidized most rapidly to its perxanthate by FMO3. Again, the derivatives with cyclic or branched side chain substituents (D609, C3iso, and 2-methyl-C3) were oxidized at a slower rate. Surprisingly the two xanthates with the longest alkyl chain substituents (C10 and C12), which are insoluble in water (stock solution dissolved in DMSO), were oxidized by FMO3 much faster than the corresponding water soluble xanthates. This difference in the kinetic properties of the two flavin monooxygenases with substrates of different lipophilicities may be due to the fact that insect cell supersomes containing FMO3 were employed for these studies. Although the concentration of DMSO in the samples was kept low (less than 1\%), an increase in catalytic activity is possible in

TABLE 2

Rate of formation of perxanthate metabolites at $347 \mathrm{~nm}$ from different xanthates (200 $\mu \mathrm{M}$ final concentration) after incubation with FMO3 $(50 \mu \mathrm{g}, 60 \mathrm{pmol}$ flavin adenine dinucleotide) in the presence of NADPH $(200 \mu \mathrm{M})$

Values are the mean of three different experiments.

\begin{tabular}{lcc}
\hline \multicolumn{1}{c}{ Xanthate } & $\mathrm{V}$ & Linear Regression $\left(r^{2}\right)$ \\
\hline & $n$ molP/min & \\
C1 & 0.34 & 0.847 \\
C2 & 0.44 & 0.958 \\
C3 & 0.78 & 0.911 \\
C3iso & 0.46 & 0.891 \\
2-Methyl-C3 & 0.38 & 0.803 \\
C4 & 0.78 & 0.998 \\
C5 & 0.84 & 0.895 \\
C8 & 0.95 & 0.860 \\
C10 & 2.54 & 0.988 \\
C12 & 3.43 & 0.985 \\
Cyclo & 0.56 & 0.835 \\
D609 & 0.38 & 0.812 \\
\hline
\end{tabular}

supersomes due to the presence of a detergent, as previously reported (Reddy et al., 2010).

\section{Antimycobacterial Activity of Different Xanthates and ETH}

The results on the antimycobacterial activity of selected xanthates relative to that of ETH are presented in Table 3. The xanthates with short-to-medium alkyl chain substituents had minimum inhibitory concentration values 10 times lower than that of ETH, whereas the minimum inhibitory concentration value of D609, a compound with a cyclic substituent, was comparable to that of ETH. As a whole, some of the xanthate analogs tested in this study showed a moderate level of bacteriostatc antimycobacterial activity, in most cases comparable or even higher than that of the reference drug ethambutol (Jadaun et al., 2007).

\section{Discussion}

The present results show that the xanthates are primarily or exclusively oxidized by EtaA to the corresponding sulfines or perxanthates, which have a maximum absorption peak at $347 \mathrm{~nm}$. The calculated kinetic parameters for production of these metabolites were faster than those for oxidation of ETH by the same enzyme. The xanthate metabolites produced by EtaA appeared to be identical to those obtained upon incubation with hydrogen peroxide. The spectral properties of the xanthates suggest that they may be useful substrates to determine FMO activity in biologic samples if the superoxide dismutase and catalase activity in these samples is present. The ready synthetic access to xanthate derivatives may provide access to compounds with higher antimycobacterial activities.

There is a large group of thiourea prodrugs with potent bacteriostatic antimycobacterial activity that must be oxidized by EtaA to exert their action. Thus, thioacetazone is oxidized into its active

TABLE 3

Antimycobacterial activity of selected xanthates and ETH as measured by the proportional method

\begin{tabular}{lc}
\hline Compound & MIC \\
\hline & $\mu M$ \\
C2 - xanthate & 1.25 \\
C5 - xanthate & 0.99 \\
C8 - xanthate & 2.05 \\
D609 & 18.8 \\
ETH & 12.0 \\
\hline
\end{tabular}

MIC, minimum inhibitory concentration. 
<smiles>CCOCCOCC</smiles><smiles>[R]OC(=S)[Se]</smiles>

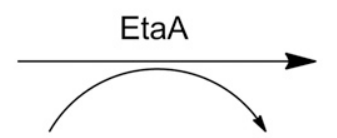<smiles>[R]OC(=S)S[O-]</smiles>

$\mathrm{NADPH} / \mathrm{O}_{2}$

\section{$\mathrm{NADP}^{+} / \mathrm{H}_{2} \mathrm{O}$}

Fig. 5. Structure of ETH and proposed scheme of $S$-oxidation of xanthates by EtaA to perxanthates. A similar reaction is mediated by human FMO3.

form, 2-ethyl-4-amidopyridine. It has a relatively low affinity $\left(K_{\mathrm{m}}=\right.$ $131 \pm 29 \mu \mathrm{M}$ ) for EtaA (Qian and Ortiz de Montellano, 2006; Alahari et al., 2007). Isoxyl (thiocarlide; $4,4^{\prime}$-diisoamyloxydiphenylthiourea) is likewise activated by EtaA, although its antimycobacterial activity differs in that it inhibits the synthesis of oleic acid as well as that of mycolic acid (Phetsuksiri et al., 2003). Other compounds with thioamide and thiourea groups, including thiobenzamide, isothionicotinamide, and prothionamide, are oxidized by EtaA and human FMO enzymes (Vannelli et al., 2002; Nishida and Ortiz de Montellano, 2011).

The spectroscopic results in the oxidation of xanthates by EtaA and the published data on the possible sulfur-oxidized metabolites implicate the following scheme in the metabolism of xanthates by EtaA (Fig. 5). The killing efficacy of different thioamide and thiourea compounds against Mtb supports the idea that it may be possible to improve their clinical application through dosage reduction, thus minimizing side effects and improving patient compliance. This approach can, in principle, be achieved by manipulating EtaA efficiency:

1. By increasing EtaA activity by boosting the enzyme gene expression; and

2. By compounds with higher affinity for EtaA, since decreasing the dose achieves the same efficacy at reduced toxicity.

In the context of a comparison of antibacterial effects of ETH and alkyl chain xanthate derivatives it should be considered that the active ETH metabolite is not ETH-SO, but the so-called ETH* (Hanoulle et al., 2006), a metabolite with still unknown molecular characteristics that accumulated within the bacterial cells while the other ETH derivatives were exclusively found in the extracellular milieu. Whether the physicochemical characteristics of the peraxanthate have allowed more efficient penetration into the bacterial cell, and therefore greater antibacterial activity, remains to be established.

In conclusion, the xanthates examined exhibit high affinity for FMOs that oxidized them to the corresponding $S$-oxides (perxanthates), apparently without altering the activating enzyme activity. They could be used as test substrates for rapid and selective determination of FMO activity in various biologic media. Xanthates have antimycobacterial activity against Mtb H37Rv comparable to that of ETH. The synthesis of further xanthate derivatives would appear to be a promising route to compounds with higher antimycobacterial activity.

\section{Acknowledgments}

T.D.S. and S.G.Y. are grateful to the Ministry of Science and Education of Bulgaria for the support of the work for the thesis of T.D.S. We thank the National Institutes of Health (Grant AI074824) for partial support of these experiments.

\section{Authorship Contributions}

Participated in research design: Yanev, Valcheva, Ortiz de Montellano. Conducted experiments: Yanev, Stoyanova, Valcheva.

Performed data analysis: Yanev, Valcheva.

Wrote or contributed to the writing of the manuscript: Yanev, Valcheva, Ortiz de Montellano.

\section{References}

Adibhatla RM, Hatcher JF, and Gusain A (2012) Tricyclodecan-9-yl-xanthogenate (D609) mechanism of actions: a mini-review of literature. Neurochem Res 37:671-679.

Alahari A, Trivelli X, Guérardel Y, Dover LG, Besra GS, Sacchettini JC, Reynolds RC, Coxon GD, and Kremer L (2007) Thiacetazone, an antitubercular drug that inhibits cyclopropanation of cell wall mycolic acids in mycobacteria. PLoS One 2:e1343.

Ballou D and Entsch B (2013) The reaction mechanisms of groups A and B flavoprotein monooxygenases, in Handbook of Flavoproteins (Hille R, Miller SM, and Palfey B eds) pp 1-28, De Gruyter, Berlin.

Banerjee A, Dubnau E, Quemard A, Balasubramanian V, Um KS, Wilson T, Collins D, de Lisle G, and Jacobs WR, Jr (1994) inhA, a gene encoding a target for isoniazid and ethionamide in Mycobacterium tuberculosis. Science 263:227-230.

Baulard AR, Betts JC, Engohang-Ndong J, Quan S, McAdam RA, Brennan PJ, Locht C, and Besra GS (2000) Activation of the pro-drug ethionamide is regulated in mycobacteria. J Biol Chem 275:28326-28331.

Beaty NB and Ballou DP (1981) The reductive half-reaction of liver microsomal FAD-containing monooxygenase. J Biol Chem 256:4611-4618.

Canetti G, Fox W, Khomenko A, Mahler HT, Menon NK, Mitchison DA, Rist N, and Smelev NA (1969) Advances in techniques of testing mycobacterial drug sensitivity, and the use of sensitivity tests in tuberculosis control programmes. Bull World Health Organ 41:21-43.

Cashman JR and Zhang J (2006) Human flavin-containing monooxygenases. Annu Rev Pharmacol Toxicol 46:65-100.

Daffé M, Quémard A, and Marrakchi H (2017) Mycolic acids: from chemistry to biology, in Biogenesis of Fatty Acids, Lipids and Membranes (Geiger O ed) pp 1-36, Springer International Publishing, Cham, Switzerland.

Hanoulle X, Wieruszeski JM, Rousselot-Pailley P, Landrieu I, Locht C, Lippens G, and Baulard AR (2006) Selective intracellular accumulation of the major metabolite issued from the activation of the prodrug ethionamide in mycobacteria. J Antimicrob Chemother 58:768-772.

Hao FP, Silvester E, and Senior GD (2000) Spectroscopic characterization of ethyl xanthate oxidation products and analysis by ion interaction chromatography. Anal Chem 72:4836-4845.

Ivanov IDTT (1956) Deterrence of xanthates on tuberculosis exciter [bul], in Proceedings of the Institute of Microbiology, Bulgarian Academy of Sciences, Sofia, Bulgaria. Vol 7, pp 6.

Jadaun GPS, Agarwal C, Sharma H, Ahmed Z, Upadhyay P, Faujdar J, Gupta AK, Das R, Gupta P, Chauhan DS, et al. (2007) Determination of ethambutol MICs for Mycobacterium tuberculosis and Mycobacterium avium isolates by resazurin microtitre assay. J Antimicrob Chemother $\mathbf{6 0}$ : $152-155$.

Johnsson K, King DS, and Schultz PG (1995) Studies on the mechanism of action of isoniazid and ethionamide in the chemotherapy of tuberculosis. J Am Chem Soc 117:5009-5010.

Krueger SK, Martin SR, Yueh MF, Pereira CB, and Williams DE (2002) Identification of active flavin-containing monooxygenase isoform 2 in human lung and characterization of expressed protein. Drug Metab Dispos 30:34-41.

Laborde J, Deraeve C, Duhayon C, Pratviel G, and Bernardes-Génisson V (2016) Ethionamide biomimetic activation and an unprecedented mechanism for its conversion into active and nonactive metabolites. Org Biomol Chem 14:8848-8858.

Nishida CR and Ortiz de Montellano PR (2011) Bioactivation of antituberculosis thioamide and thiourea prodrugs by bacterial and mammalian flavin monooxygenases. Chem Biol Interact 192: $21-25$.

Phetsuksiri B, Jackson M, Scherman H, McNeil M, Besra GS, Baulard AR, Slayden RA, DeBarber AE, Barry CE, III, Baird MS, et al. (2003) Unique mechanism of action of the thiourea drug isoxyl on Mycobacterium tuberculosis. J Biol Chem 278:53123-53130.

Phillips IR and Shephard EA (2017) Drug metabolism by flavin-containing monooxygenases of human and mouse. Expert Opin Drug Metab Toxicol 13:167-181.

Poulsen LL and Ziegler DM (1995) Multisubstrate flavin-containing monooxygenases: applications of mechanism to specificity. Chem Biol Interact 96:57-73.

Qian L and Ortiz de Montellano PR (2006) Oxidative activation of thiacetazone by the Mycobacterium tuberculosis flavin monooxygenase EtaA and human FMO1 and FMO3. Chem Res Toxicol 19:443-449.

Rao SR (1971) Xanthates and Related Compounds, Marcel Dekker, Inc., New York.

Reddy RR, Ralph EC, Motika MS, Zhang J, and Cashman JR (2010) Characterization of human flavin-containing monooxygenase (FMO) 3 and FMO5 expressed as maltose-binding protein fusions. Drug Metab Dispos 38:2239-2245.

Silvester E, Truccolo D, and Hao FP (2002) Kinetics and mechanism of the oxidation of ethyl xanthate and ethyl thiocarbonate by hydrogen peroxide. J Chem Soc, Perkin Trans 2: $1562-1571$.

Vannelli TA, Dykman A, and Ortiz de Montellano PR (2002) The antituberculosis drug ethionamide is activated by a flavoprotein monooxygenase. J Biol Chem 277:12824-12829.

Zhang Y, Heym B, Allen B, Young D, and Cole S (1992) The catalase-peroxidase gene and isoniazid resistance of Mycobacterium tuberculosis. Nature 358:591-593.

Address correspondence to: Stanislav G. Yanev, Department of Drug Toxicology, Institute of Neurobiology, Bulgarian Academy of Sciences, Acad. G. Bonchev Str., Block 23, BG-1113 Sofia, Bulgaria. E-mail: stanislav_yanev@yahoo.com 